\title{
Synchronous development and release of broods by the swarming mysids Anisomysis mixta australis, Paramesopodopsis rufa and Tenagomysis tasmaniae (Mysidacea: Crustacea)
}

\author{
N. M. Johnston*, D. A. Ritz** \\ School of Zoology, University of Tasmania, Box 252-5, GPO Hobart, 7001 Tasmania, Australia
}

\begin{abstract}
Individual in vivo broods of the swarming mysid species Anisomysis mixta australis, Tenagomysis tasmaniae and Paramesopodopsis rufa developed synchronously and at rates identical to those cultured in vitro. Hence it appears that the parent does not influence the synchrony of development. Synchronous development was also evident among $P$. rufa females within swarms and a strong peak of release of their brood was evident over 1 or 2 nights. In contrast, swarms of the sympatric species A. mixta australis and T. tasmaniae released their young in a staggered fashion over a longer time period. At the time of emergence from the marsupium, young are vulnerable to cannibalism from adults and older juveniles. Newborn young moulted within 30 min of emergence from the marsupium. Both pre-moult and post-moult juveniles were cannibalised by older life stages, though the former were eaten in larger numbers probably because post-moult newborns were more agile swimmers. Pre-moult newborns were not cannibalised by the parent females though they became vulnerable after the first moult. Whether the strategy of synchronous development and release is manifested in mysid swarms may depend on the size of the swarm. For species that form relatively small swarms (up to 1000 individuals), such as P. rufa, synchronous release from a large number of females may be important to promote early swarming among newly liberated juveniles. Synchronous release may be less important for the reproductive success of species that form larger swarms that continuously release large numbers of young, such as A. mixta australis and $T$. tasmaniae.
\end{abstract}

KEY WORDS: Mysid · Crustacea $\cdot$ Anisomysis mixta australis $\cdot$ Paramesopodopsis rufa $\cdot$ Tenagomysis tasmaniae · Larval development · Swarms · Synchronous development · Synchronous release · Cannibalism

Resale or republication not permitted without written consent of the publisher

\section{INTRODUCTION}

The phenomenon of synchronous development and release of young from large numbers of females has been unevenly documented for aquatic crustaceans. Most investigations have been confined to members of the Brachyura, where larval release coincides with lunar, diel and tidal cycles (DeCoursey 1983, Forward

\footnotetext{
*Present address: University of Cambridge, Downing St., Cambridge CB2 3EJ, United Kingdom

**Corresponding author. E-mail: david.ritz@utas.edu.au
}

1987, Saigusa \& Kawagoye 1997). Until now, there have been no reports of mass release of young among social peracarids.

In all peracarid crustaceans, the developing young are retained within a brood pouch (or marsupium) until they reach a stage where they resemble miniature adults. In mysids, the developing larvae within a single marsupium are at the same stage of development and are released from the brood pouch over 1, or a maximum of 2, nights (Green 1970, Mauchline 1980). Mysids are cannibalistic, and smaller (younger) individuals are commonly preyed upon by larger (older) ones (Berrill 1969, Wittmann 1978, Reitsema \& Neff 
1980, Wittmann 1981a,b, Fenton 1992). Gregarious mysids generally form size- and age-segregated swarms, which has the effect of reducing such predation pressure (Clutter 1969, O'Brien 1988, Modlin 1990). However, juveniles are released within the vicinity of adults and are therefore vulnerable to predation until they seek refuge outside the adult swarm.

Pulliam \& Caraco (1984) suggest that individuals may reduce per capita predation on offspring by synchronising births in time, even if aggregations attract predators. The advantage is postulated to be that predators might be satiated quickly. A consequence of group birthing may therefore be increased survival of offspring compared with asynchronous births. This reproductive strategy may be important in mysids. An additional advantage in social species is that newborns may aggregate at an early stage, thereby gaining protection against predation as well as other group benefits (Ritz 1994).

Other authors have noted ways in which female mysids may reduce cannibalism on their offspring. Green (1970) and Wittmann (1982) reported that females of Acanthomysis sculpta and Leptomysis lingvura release their young during the evening to avoid predation by visual predators and by members of their own swarm, which feed primarily during the day. Wooldridge (1981) described how females of the beach mysid Gastrosaccuss psammodytes, carrying late-stage young, leave the main swarm and move to areas further from the wave splash zone to subsequently release their young. This behaviour not only would reduce the premature loss of larvae from the marsupium by wave action (Wooldridge 1981) but also may reduce predation pressure upon newborns. We have suggested elsewhere that the pre-moult juvenile cuticle of some mysid species may contain a chemical signal that inhibits feeding by the parent female.

The 3 mysid species Anisomysis mixta australis, Tenagomysis tasmaniae and Paramesopodopsis rufa are sympatric in southeast Tasmanian waters, forming monospecific swarms in daytime with slightly different habitat and depth preferences (Fenton 1992). Natural swarm sizes vary considerably among the species: $P$. rufa typically forms small aggregations of up to 1000 individuals, whereas the other 2 form large aggregations up to and sometimes exceeding 10000 individuals (O'Brien 1988). Swarm size can determine food capture success and level of protection from predation (Ritz 1997). We postulate that swarm size may exert a selection pressure for a higher level of synchrony of brood development and release because if too few young are released simultaneously to constitute a viable swarm, these young would be vulnerable to predation and starvation.
It has already been established that all young within an individual brood pouch of Anisomysis mixta australis, Tenagomysis tasmaniae and Paramesopodopsis rufa develop synchronously when cultured in vitro (Johnston et al. 1997). The aims of this study were to determine, firstly, whether in vivo development and release of individual broods of these species is synchronous and, if so, whether development times differ from those recorded for in vitro embryos - i.e., does the parent female play a role in synchrony? A second aim was to investigate whether synchronous development and release of young within individual swarms occurs and, if so, whether there is a different pattern in the 3 species. The third aim was to examine mechanisms that may minimise cannibalism of newly released juveniles.

\section{MATERIALS AND METHODS}

Field collection. Synchrony within individual broods: Sub-samples of 20 individual swarms of Anisomysis mixta australis, Tenagomysis tasmaniae and Paramesopodopsis rufa were collected from 2 sites in southeast Tasmania, Taroona Beach $\left(42^{\circ} 56^{\prime} \mathrm{N}, 147^{\circ} 21^{\prime} \mathrm{E}\right)$ and Kingston Beach $\left(42^{\circ} 59^{\prime} \mathrm{N}, 147^{\circ} 19^{\prime} \mathrm{E}\right)$ close to the shore, following methods outlined in Johnston et al. (1997). For each species, 10 swarms were sampled along a transect at Site 1 and a further 10 swarms were sampled along a transect at Site 2. At the collection sites, A. mixta australis and T. tasmaniae often formed swarms that extended up to $4 \mathrm{~m}$ in length and $2 \mathrm{~m}$ in depth. Sub-samples of the swarms were taken as it was impossible to capture an entire swarm using a hand net. Although $P$. rufa formed much smaller, ovoid swarms (approximately $1 \mathrm{~m}$ in diameter), they moved very quickly through the water, making it impracticable to collect an entire swarm. As a result sub-samples of $P$. rufa swarms were also taken. Mysids were collected along transects at the 2 collection sites so that individual swarms were sub-sampled only once. Following collection the specimens were immediately preserved in $5 \%$ buffered formalin.

Synchrony of larval release within swarms: The 3 species form monospecific swarms in similar nearshore habitats but each selects a particular microhabitat (Fenton 1992). Three replicate swarms of Anisomysis mixta australis, Paramesopodopsis rufa and Tenagomysis tasmaniae were caught at the collection sites in the same manner as described above; however, these were transported live back to the laboratory using methods described by Johnston et al. (1997).

Laboratory methods. Synchrony of larval development: The broods of 300 females (sometimes fewer) of each species from each sub-sampled swarm were 
examined and the stage of development of the brood was determined according to Wittmann's (1981a) classification:

- E1: embryonic stage 1 (1- and 40-celled stage);

- E3: embryonic stage 3 (germinal disc on ventral surface, optical rudiments present);

- E5: embryonic stage 5 (well-developed nauplioid appendages, embryonic abdomen folded over germ);

- N1: nauplioid stage 1 (freshly hatched nauplii, larval abdomen and nauplius appendages project freely);

- N2: nauplioid stage 2 (yolk intrudes into abdomen, body segmentation visible);

- N4: nauplioid stage 4 (late nauplioid shortly before moult);

- P2: post-nauplioid stage 2 (post-nauplioid with all appendages and carapace freed);

- P4: post-nauplioid stage 4 (free living stage).

Synchrony of release: Three individual swarms, each of 20 ovigerous females carrying E3 stage larvae, of Anisomysis mixta australis, Tenagomysis tasmaniae and Paramesopodopsis rufa were cultured in aquaria (water temperature $17^{\circ} \mathrm{C}$ ) using methods modified from the design described by Reitsema \& Neff (1980). In its original design the system consisted of 2 glass aquaria: ovigerous female mysids held in 1 released young that were gently siphoned using a pump into a trap in the other through mesh-protected funnels. This arrangement proved not to remove all newly emerged young from the main tank. In our system single culture tanks were modified so that all newly liberated young were removed from the main aquarium. Firstly, the tank was separated into 2 sections by a nylon mesh screen $(500 \mu \mathrm{m})$ held in place by silicone cement. Juveniles could pass through but adults were restricted to 1 side. Two ceramic funnels covered with $100 \mu \mathrm{m}$ nylon mesh were placed in 1 section and were connected by hose to peristaltic pumps and filters (Eheim, Germany). Outlets from the pumps returned water to the other section of the tank in which ovigerous female mysids were held. Emerging juveniles, assisted by the unidirectional current, swam through the mesh partition and gained a refuge from adults. Black paper secured to the outside of the rear and side walls of the tank made the pale juveniles more visible. Newly released young were collected and numbers recorded each morning until no more were found.

Moulting of newly released juveniles and parent female: Females of the 3 species, incubating late-stage young as indicated by deeply pigmented eyes visible through the marsupial wall, captured as described above, were held singly in 21 dark-coloured plastic containers. Dark container walls facilitated collection of transparent exuvia of both adults and young. It had previously been noted that release occurs at night so 3 females, the maximum number that could be monitored simultaneously, were observed each evening under dim red light $(\sim 10 \mathrm{~lx})$. In total 6 females of each species were monitored in this way. Temperature was $17 \pm 1^{\circ} \mathrm{C}$, salinity was $35 \pm 1$ psu and photoperiod was 15:9 (overhead fluorescent light). Stress on the animals was minimised by conducting experiments in a quiet room, and sudden movements were avoided.

Once all young had been released, the containers were inspected for juvenile exuvia, and the number of newborn young was recorded. These were removed from the container and the adult females left until 08:00 $\mathrm{h}$ the following morning, when the containers were again inspected for adult exuvia.

Cannibalism on newly released juveniles: Four containers of pre-moult and 4 of post-moult juveniles, each containing 20 individuals in 21 of seawater, were set up. Temperature, salinity and light conditions were as previously described. One individual of 1 of the following life stages was placed in each of the containers with the juveniles: (1) non-ovigerous adult female; (2) ovigerous female; (3) adult male; and (4) older juvenile. The experiment was run for $2 \mathrm{~h}$. At the end of this period the number of newly released juveniles remaining was recorded. Six replicates were run for each of the 3 species. These experiments give only a relatively crude estimate of the potential for cannibalism because no alternative prey were offered and young were not provided with refuges.

First signs of gregariousness: A swarm of approximately 300 individuals was established in a glass aquarium $(80 \times 40 \times 45 \mathrm{~cm})$ containing $80 \mathrm{l}$ of seawater (35 $\pm 1 \mathrm{psu}$ ) that had been filtered to reduce particulate matter. Removal of this group of mysids from a holding tank using a coarse mesh net through which small individuals could pass ensured that no juveniles were present before the experiment began. The swarm contained many females carrying well-developed young, as indicated by pigmented eyes visible through the marsupial wall. The aquarium was illuminated only by an infrared source, and behaviour of the mysids was recorded using an infrared sensitive video camera (Radio Parts Group PT 5043, Melbourne) connected to a Panasonic VCR (model NVFS 100; Masushita Electric Industrial Co., Osaka, Japan) and National monitor (model WV 5410). Circulation provided by gentle aeration did not affect the ability of weakly swimming juveniles to aggregate. Once in the experimental aquarium, the swarm was left to acclimatise for $2 \mathrm{~h}$ before filming commenced ( $1 \mathrm{~h}$ before darkness outside). Footage was later inspected for position of newly released juveniles relative to the adult swarm and for females that had remained in the swarm while releasing their brood. Three separate swarms of each species were observed on different occasions. 
Statistical methods. Synchrony of larval development: $\chi^{2}$ tests were performed for each species to determine whether there were significant differences in the distribution of embryonic stages carried by females of a swarm. If not, the data from the replicate swarms were pooled for each species and the $\chi^{2}$ test was repeated for every combination of species pairs. Because of the large quantity of data and subsequent power of the $\chi^{2}$ test, the level of significance was adjusted to 0.017 using the Bonferroni correction (Zar 1984).

Synchrony of release: The data were tested for normality and homogeneity of variances, and transformation was found to be unnecessary. A 1-way, fixedfactor ANOVA was performed to determine whether there were differences between species in the maximum number of juveniles released on any day. This was followed by a post-hoc comparison of means (Tukey test) to identify any pairwise differences.

All analyses were performed using SYSTAT 5.2 (Microsoft Inc., Redmond, WA, USA).

Cannibalism on newly released juveniles: Two-way ANOVAs were conducted for each species to determine differences in (1) the number of newborn young consumed by different life stages and (2) the number of pre-moult and post-moult juveniles consumed. A separate 2-way ANOVA was conducted to compare differences in pre-moult and post-moult juveniles consumed between species. All analyses were performed using SYSTAT 5.2.

\section{RESULTS}

\section{Synchrony of intra-swarm larval development}

There was no significant difference between in vivo and in vitro development times (defined here as time taken in days from stage $\mathrm{E} 2$ to release) for the 3 species (Table 1). Free-living juveniles of Anisomysis mixta australis were released after $14 \mathrm{~d}$ (compared with $14.5 \mathrm{~d}$ in vitro), Tenagomysis tasmaniae after $14.5 \mathrm{~d}$ (compared with $14.8 \mathrm{~d}$ in vitro) and Paramesopodopsis rufa after nearly $19 \mathrm{~d}$ (compared with $19.8 \mathrm{~d}$ in vitro) (in vitro data from Johnston et al. 1997).

The $\chi^{2}$ tests indicated that, for a given species, there was no significant difference among replicate swarms in the proportion of females carrying various stage larvae (Anisomysis mixta australis: $\chi^{2}=51.061, \mathrm{df}=6$, $\mathrm{p}>0.99$; Tenagomysis tasmaniae: $\chi^{2}=43.054, \mathrm{df}=6, \mathrm{p}>$ 0.99; Paramesopodopsis rufa: $\chi 2=317.806, \mathrm{df}=6$, $\mathrm{p}>0.99$ ). Thus, the data for each species were pooled.

The subsequent $\chi^{2}$ tests showed that among all 3 species, there was a significant difference $\left(\chi^{2}=\right.$ 915.679, df $=12, \mathrm{p}<0.017$ ) in the proportion of various stage larvae (from pooled swarms) (Table 2a).
Table 1. Results of ANOVA comparing the difference between in vitro and in vivo incubation times for (a) Anisomysis mixta australis, (b) Tenagomysis tasmaniae and (c) Paramesopodopsis rufa. In vitro development times are from Johnston et al. (1997); ns: not significant

\begin{tabular}{|c|c|c|c|c|c|}
\hline Source & SS & DF & MS & F-ratio & $\mathrm{p}$ \\
\hline \multicolumn{6}{|c|}{ (a) A. mixta australis } \\
\hline Culture method & 0.100 & 1 & 0.100 & 0.506 & $0.481 \mathrm{~ns}$ \\
\hline Error & 7.500 & 38 & 0.197 & & \\
\hline \multicolumn{6}{|l|}{ (b) T. tasmaniae } \\
\hline Culture method & 0.025 & 1 & 0.025 & 0.062 & $0.804 \mathrm{~ns}$ \\
\hline Error & 15.35 & 38 & 0.404 & & \\
\hline \multicolumn{6}{|l|}{ (c) P. rufa } \\
\hline Culture method & 0.025 & 1 & 0.025 & 0.077 & $0.783 \mathrm{~ns}$ \\
\hline Error & 12.35 & 38 & 0.325 & & \\
\hline
\end{tabular}

Table 2. (a) Results of $\chi^{2}$ test comparing the distribution of larvae at various stages among females of A. mixta australis (Am), P. rufa (Pr) and T. tasmaniae (Tt). (b) Results of pairwise $\chi^{2}$ tests of the differences in distribution of larval stages among females of Am, Tt and Pr from pooled swarms. * Significant difference after applying a Bonferroni correction $(\mathrm{p}<0.017)$

\begin{tabular}{|lcc|}
\hline (a) & $\chi^{2}{ }_{(12)}$ & $\mathrm{p}$ \\
\hline $\mathrm{Am} \times \mathrm{Tt} \times \mathrm{Pr}$ & 915.679 & $<0.001$ \\
(b) & $\chi^{2}{ }_{(6)}$ & $\mathrm{p}$ \\
\hline $\mathrm{Am} \times \mathrm{Tt}$ & 15.832 & 0.015 \\
$\mathrm{Am} \times \mathrm{Pr}$ & 825.596 & $<0.001^{*}$ \\
$\mathrm{Pr} \times \mathrm{Tt}$ & 703.777 & $<0.001^{*}$ \\
\hline
\end{tabular}

Pairwise comparisons of the number of females carrying various stage larvae between Anisomysis mixta australis and Paramesopodopsis rufa, and P. rufa and Tenagomysis tasmaniae were significant $\left(\chi^{2}=825.596\right.$, $\mathrm{df}=6, \mathrm{p}<0.017$ and $\chi^{2}=703.777, \mathrm{df}=6, \mathrm{p}<0.017$, respectively). That between $A$. mixta australis and $T$. tasmaniae was considered non-significant $\left(\chi^{2}=15.832\right.$, $\mathrm{df}=6, \mathrm{p}=0.015)$ because of its similar $\mathrm{p}$-value to the Bonferroni corrected $p$-value (0.017) (Table 2b).

Fig. 1 shows that there was no peak in the proportion of larvae of any particular stage of development in females from pooled swarms of Anisomysis mixta australis. For this species 12 to $17 \%$ of the total number of intra-swarm females carried young of each larval stage. A similar pattern (13 to $15 \%$ ) was observed for Tenagomysis tasmaniae. However, for Paramesopodopsis rufa there was a pronounced peak in the number of intra-swarm females carrying E3 larvae $(46 \%)$ and only 6 to $19 \%$ carrying young of each of the remaining 6 larval stages. No statistical analysis was 
applied to the distribution of various-stage young within swarms of each species because the trends were clear and consistent.

\section{Synchrony of individual release}

Results showed that the process and timing of brood release were similar in all 3 species. Females released their broods within $30 \mathrm{~min}$ of commencement of the period of darkness (21:00 to 21:30 h). Females aided the release of young by pumping their oostegites. The time taken for all juveniles to emerge from individual marsupia was approximately $1 \mathrm{~h}$.

\section{Synchrony of release within swarms}

For each replicate swarm of Anisomysis mixta australis, the maximum proportion of newly released juveniles $\mathrm{d}^{-1}$ was between 12 and $22 \%$ of the total number of juveniles released throughout the experiment (Fig. 2). The maximum number of newly released Tenagomysis tasmaniae juveniles $\mathrm{d}^{-1}$ was 14 to $18 \%$ (Fig. 3), and the maximum number of newly released Paramesopodopsis rufa juveniles $\mathrm{d}^{-1}$ was much higher, i.e., 40 to $45 \%$ (Fig. 4). There was a constant, low level of release throughout the period of observation for $A$. mixta australis and T. tasmaniae. However, there was a strong peak in the number $P$. rufa juveniles released over 1 or $2 \mathrm{~d}$.

The ANOVA indicated that the differences between species in the maximum number of juveniles released on any day were highly significant $\left(F_{2,6}=58.441\right.$, p < 0.001). A Tukey test showed that differences in these maxima were highly significant between Paramesopodopsis rufa and Anisomysis mixta australis ( $\mathrm{p}<$ $0.017)$, and $P$. rufa and Tenagomysis tasmaniae $(\mathrm{p}<0.017)$; however, there was no significant difference between $A$. mixta australis and $T$. tasmaniae $(\mathrm{p}=0.936)$.

\section{Moulting by newly released juveniles and parents}

Following release, a juvenile would sink to the bottom of the container and begin violently twitching its body. Invariably it moulted within $30 \mathrm{~min}$ of emergence. Exuviation lasted from 0.5 to $1 \mathrm{~min}$. After completion of exuviation the juveniles swam freely in the container. When they came into contact with the parent, they displayed a tail flick escape response characteristic of mysids. Females of the 3 species did not attempt to feed on their young during release; however, they fed on young after the latter had undergone
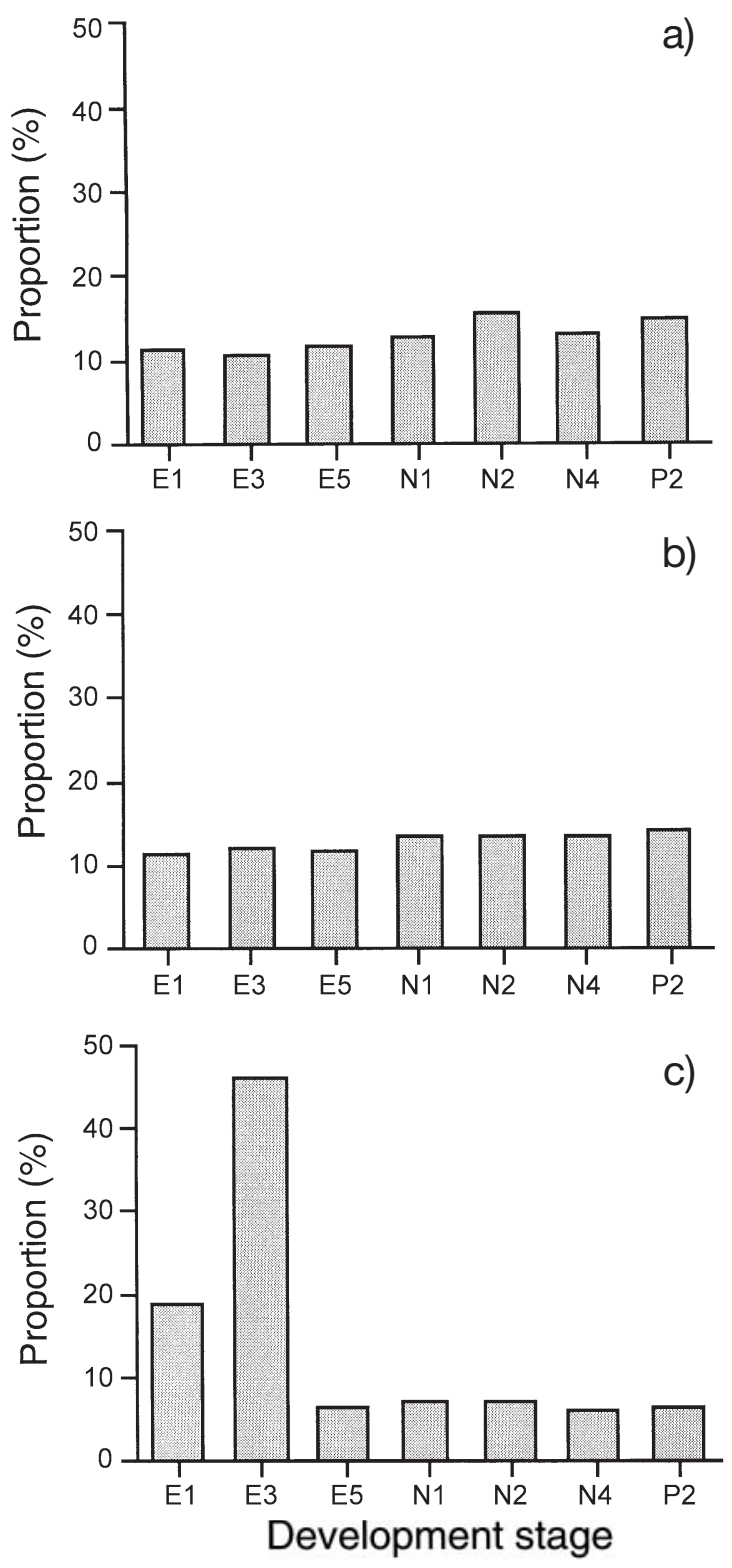

Fig. 1. Proportion of females (\%) in swarms of (a) Anisomysis mixta australis, (b) Tenagomysis tasmaniae and (c) Paramesopodopsis rufa, carrying young at various stages. Data are pooled from 20 swarms of each species. E: embryonic stages; $\mathrm{N}$ : nauplioid stages; P: post-nauplioid stages

the first moult outside the pouch. Presence of adult exuviae in the containers on the morning following release indicated that females of the 3 species moulted during the same night as releasing their young.

\section{Cannibalism on newly released young}

Females of all 3 species remained within a swarm while releasing their young. 

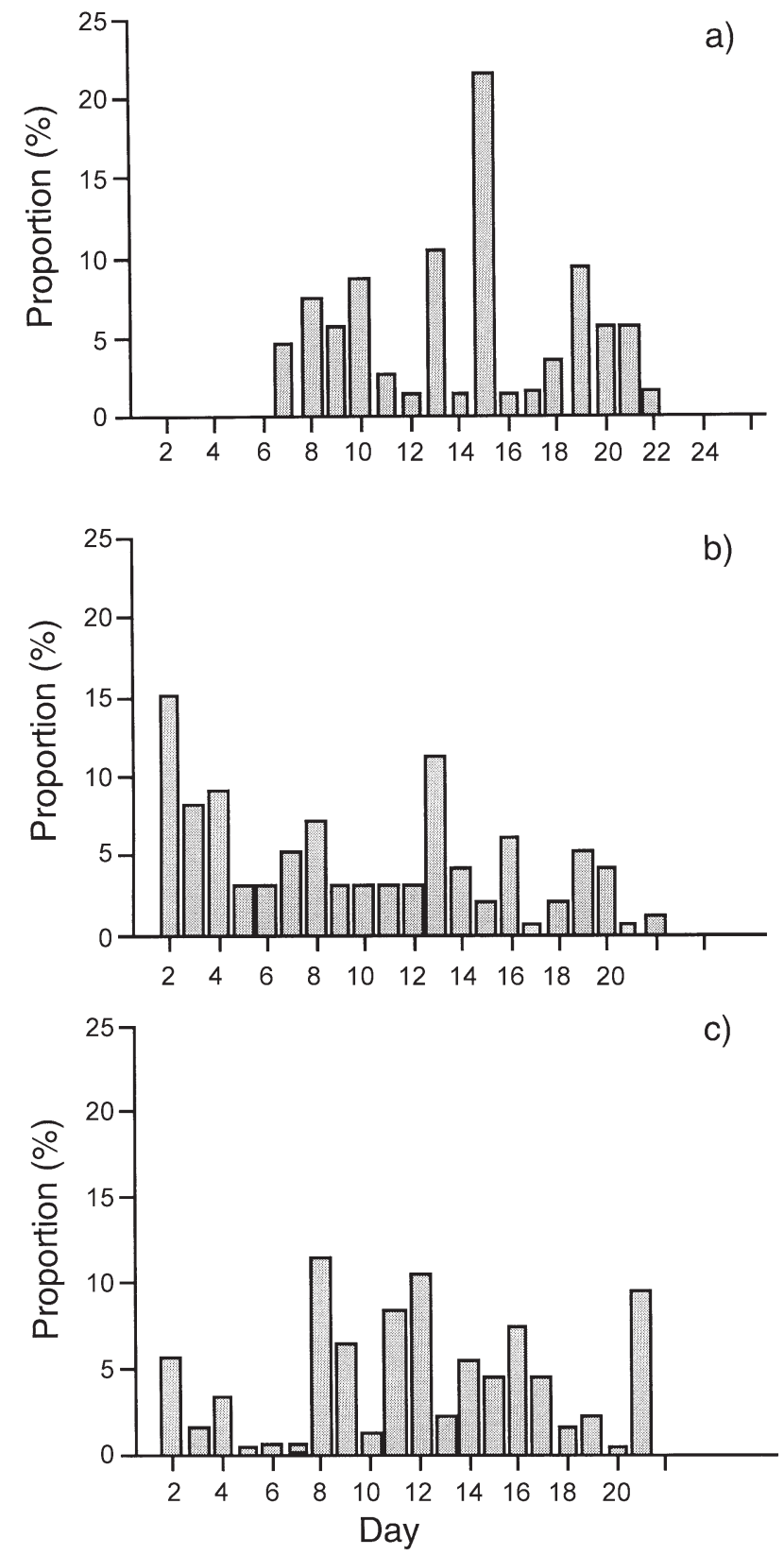

Fig. 2. Number of juveniles released $\mathrm{d}^{-1}$ (expressed as \% of total) from 3 swarms $(\mathrm{a}, \mathrm{b}, \mathrm{c})$ of Anisomysis mixta australis

There was no significant difference in the total number of newborns consumed by any of the different life stages for Anisomysis mixta australis (ANOVA $F_{3,40}=$ $0.14, \mathrm{p}=0.993)$ and Tenagomysis tasmaniae $\left(F_{3,40}=\right.$ $0.28, \mathrm{p}=0.839)$. However, there was a significant difference for Paramesopodopsis rufa $\left(F_{1,30}=45.60, \mathrm{p}<\right.$ 0.001).

For all species, the number of pre-moult juveniles consumed was significantly greater than the number of post-moult juveniles (ANOVA Anisomysis mixta australis $F_{1,40}=152.14, \mathrm{p}<0.001$; Tenagomysis tasmaniae
$F_{1,40}=156.03, \mathrm{p}<0.001 ;$ Paramesopodopsis rufa $F_{2,30}=$ $19.68, \mathrm{p}<0.001)$. There was no significant difference between species in their preference for pre-moult juveniles but there was in total number consumed between A. mixta australis and T. tasmaniae ( $\mathrm{p}<$ $0.001)$ and between $T$. tasmaniae and P. rufa ( $\mathrm{p}<$ 0.001). Total number of newborns consumed did not differ between $P$. rufa and $A$. mixta australis ( $p=$ 0.228 ).

\section{DISCUSSION}

Mysid broods cultured in vivo in individual marsupia, from stage E3 to free-living juveniles, developed synchronously and at an identical rate to those cultured in vitro (Johnston et al. 1997). This indicates that the female parent does not influence the synchrony of development. Maternal care of the brood is restricted to aeration and protection of the eggs. The mother also aids in the release of young by vigorous pumping of the oostegites (Wittmann 1981b, present study).
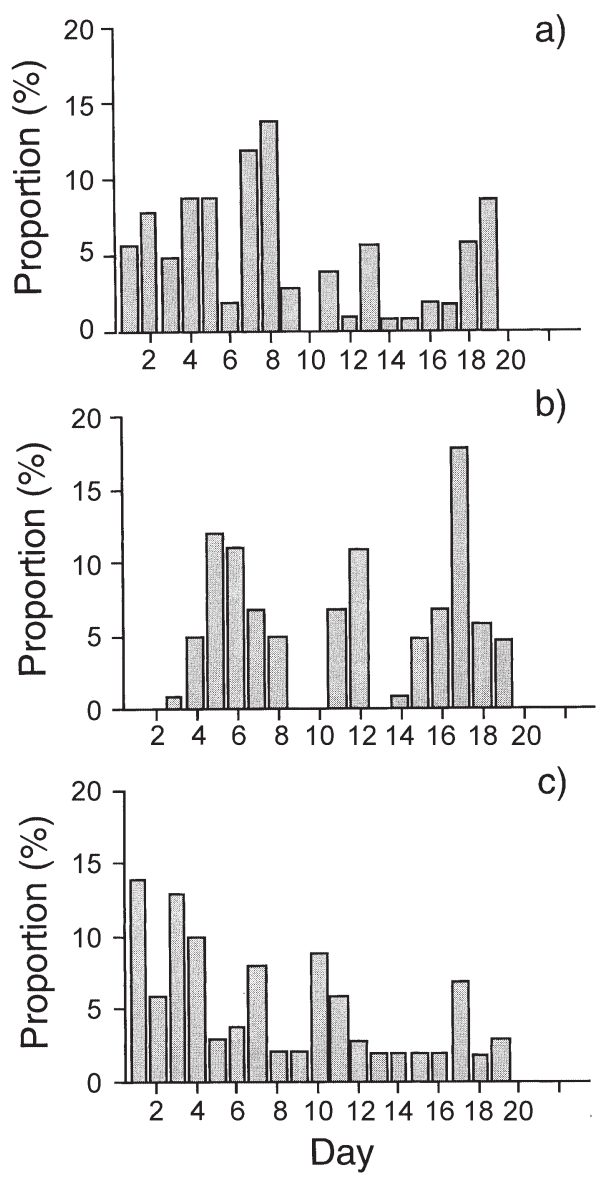

Fig. 3. Number of juveniles released $\mathrm{d}^{-1}$ (expressed as \% of total) from 3 swarms $(\mathrm{a}, \mathrm{b}, \mathrm{c})$ of Tenagomysis tasmaniae 

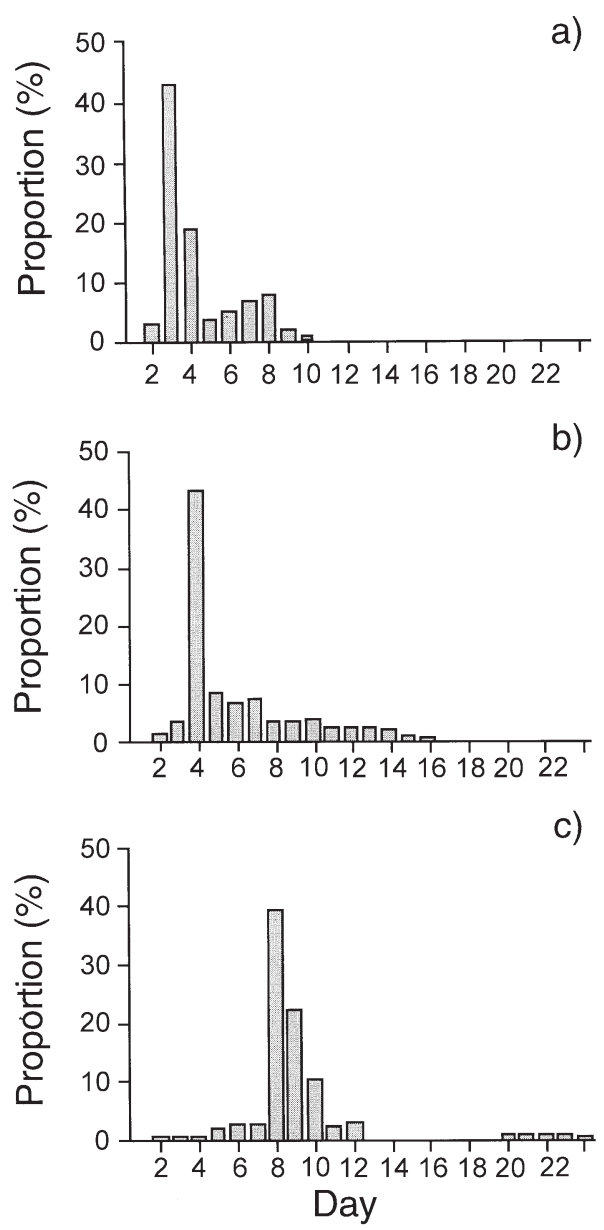

Fig. 4. Number of juveniles released $\mathrm{d}^{-1}$ (expressed as \% of total) from 3 swarms $(\mathrm{a}, \mathrm{b}, \mathrm{c})$ of Paramesopodopsis rufa

Reports of synchronous development in other peracarids are sparse. Among the amphipods, Talitrus is known to exhibit synchrony in field-collected specimens, but little is known of the method of control (Williams 1979). A higher level of maternal care is apparent in terrestrial isopods and amphipods; the female provides the developing young with nutrients and minerals to harden the exoskeleton (Friend \& Richardson 1986, Warburg 1993). Freshwater amphipods are subject to more unstable conditions and as a consequence retain their young in the marsupium until availability of mineral and nutrient resources becomes favourable for their survival upon release (Shillaker \& Moore 1987). A high level of maternal care is possibly unnecessary in marine amphipods since essential minerals are more abundant in this environment. Because Anisomysis mixta australis, Tenagomysis tasmaniae and Paramesopodopsis rufa live in nearshore shallow water environments, where food resources are unlikely to be limiting, delaying release of the brood until conditions are favourable may not be necessary.
Results of this study revealed that synchronous development and release of young was also apparent in individual swarms of Paramesopodopsis rufa. Swarms of Anisomysis mixta australis and Tenagomysis tasmaniae, however, did not show signs of synchronous development and release. Instead, the young of these species were released in a staggered fashion over a longer time period. Work by Fenton (1994) supports the hypothesis that the peak in P. rufa females carrying E3 larvae is a result of synchronous intraswarm development rather than proportionately longer durations of this stage. The ambient water temperature was $17^{\circ} \mathrm{C}$ when the animals investigated in the present study were collected. At this temperature, Fenton (1992) found that E3 is one of the shortest larval stages, lasting only $2.4 \mathrm{~d}$ compared with E5, which lasts $4.9 \mathrm{~d}$ at the same temperature. In contrast to $P$. rufa, the distribution of various-stage young in swarms of $A$. mixta australis and $T$. tasmaniae reflects a lack of synchronous intra-swarm development. If the females of $P$. rufa in swarms do not play a role in synchronising the development of their broods, some unknown factor(s) must be involved. This may be an endogenous factor such as rate of substrate or yolk utilisation or environmental conditions, such as temperature, salinity and photoperiod. Alternatively the developing broods may release external metabolites that accumulate and are recirculated in currents produced by the swarm (Ritz 2000). In some crustacean species, hatching time is apparently controlled by the embryos themselves (Ennis 1973, Forward \& Lohmann 1983) even though developmental synchrony may be the result of an interaction between embryos and female (DeVries et al. 1991).

Synchrony of larval release from large numbers of females has been well documented in some crustacean groups such as Copepoda, Brachyura, Astacura and Palinura. Larval release in brachyurans corresponds to lunar, diel and tidal cycles (DeCoursey 1983, Forward 1987); eggs usually hatch during the dark phase of the diel cycle and often near the high tide of a tidal cycle. Detailed studies of crabs (Forward \& Lohmann 1983, DeVries et al. 1991), fiddler crabs (DeCoursey 1979) and lobsters (Ennis 1973, McCoy \& Leachman 1982) indicate that larval release lasts only a few minutes and is encouraged by vigorous abdominal and pleopod pumping (DeCoursey 1983, Forward \& Lohmann 1983). In some species of astacurans release is again regulated by the female (Branford 1978). Recent work by Saigusa \& Kawagoye (1997) suggests that hatching of Hemigrapsus sanguineus eggs is initiated by a chemical transmitted from female to embryos. The same is true in the barnacle Balanus (Semibalanus) balanoides where a hatching factor is liberated from the parent into the mantle cavity (Holland et al. 1985). 
This is apparently not the case in the mysids described here since development times in vitro and in vivo were identical. However, our data are consistent with the idea of a fixed 'hatching program' (Saigusa \& Kawagoye 1997) that is brought into synchrony in all females of a swarm in the case of Paramesopodopsis rufa but not in the other mysids in this study.

There are advantages associated with synchronous development and release of young from an individual female. It has been suggested that synchronous release of larval decapods over a short time interval serves to swamp potential predators (Forward 1987). Releasing larvae around the time of nighttime high tide also serves to rapidly remove larvae from the adult decapod population at a time of reduced activity of visual planktivorous predators (Saigusa 1981). Crabs and lobsters that release their larvae at night may do so to reduce predation on adults and larvae by visual predators (Ennis 1973, DeCoursey 1979, DeVries et al. 1991). During nocturnal larval release, females expose themselves near or at the entrance of their burrows and are therefore still at risk of predation (Forward \& Lohmann 1983). Abdominal pumping actions associated with larval release are energetically expensive (DeVries et al. 1991). Hence, the concentration of larval release behaviours during 1 night, when larvae are ready to hatch, may decrease the risk of predation on the females and offspring, and reduce the energetic cost associated with larval release. Morgan \& Christy $(1994,1995)$ have reviewed work on synchronous release of gametes or larvae by marine animals and concluded that the key factor selecting for this phenomenon is predation on newly hatched larvae. This may also be true in the case of mysids because newborn young are vulnerable to predation by conspecific adults and juveniles as indicated by experiments described above. However, since the swarm or school is a protective strategy in social aquatic species (Ritz 1994), the speed with which newborns aggregate may be a critical survival factor.

The phenomenon of synchronous development and release of young from individual swarms may be correlated with the number of individuals within the swarm. Swarms of Anisomysis mixta australis and Tenagomysis tasmaniae are large in comparison with those of Paramesopodopsis rufa, comprising up to and frequently exceeding 10000 individuals; whereas swarms of $P$. rufa are generally much smaller, containing between 5 and 1000 individuals (O'Brien 1987). If the number of individuals, particularly gravid females, in a swarm is high (e.g., A. mixta australis and $T$. tasmaniae), asynchronous development and release would still provide sufficient numbers of newly released young to form viable swarms. If the number of gravid females in a swarm is low (e.g., $P$. rufa), synchronous development and release of young may be essential to ensure that there is a sufficient number of juveniles to aggregate into a swarm. If swarms do not form immediately after the juveniles are released, some of the critical advantages of the gregarious habit would be lost. Increased alertness, defence against predators, location of food patches and food capture success, and maintenance of position in the environment are considered to be the most important advantages of gregariousness to mysids (O'Brien 1988, Ritz 1994, 1997). In such instances, the average fitness of individual group members is generally thought to increase as some function of increasing group size, up to an optimum size, and to decrease thereafter (Emlen 1984, Ritz 1997). Therefore, the individual fitness of newborn mysids is increased if they can form an optimum swarm size with members of their own size as soon as possible after release. For mysids with smaller swarm sizes, such as $P$. rufa, sufficient swarm size may only be achieved by adopting a strategy of synchronous release. We do not know the reason for the differences in swarm size among these species, but Fenton (1996) showed that T. tasmaniae had a much higher population density than the other species at her study site. It is also the most herbivorous of the 3 species. It may be significant that $P$. rufa is the most carnivorous of the 3 species (Metillo \& Ritz 1993).

Newborn young are vulnerable to cannibalism by animals in all older life stages. Pre-moult newborns were consumed more readily than post-moult, probably because the latter are more agile swimmers. Females did not feed on their own offspring immediately after release but did feed on post-moult individuals. This suggests that the pre-moult cuticle may contain a factor that inhibits feeding by the parent. The same or similar factor may aid in kin recognition leading to the phenomenon of adoption (Wittmann 1978, Johnston \& Ritz unpubl. data) in which young embryos prematurely ejected from the marsupium are reinserted if offered back to the parent.

The main conclusion from this work is that one of the mysid species studied, Paramesopodopsis rufa, shows a high level of synchrony of brood development and release within discrete swarms. We have suggested that this is related to the fact that adult $P$. rufa form the smallest aggregations of the 3 species. Without synchronised release the juveniles may lose the advantages of rapidly joining a viable cohesive swarm, which is a successful protective strategy against predation as well as providing many other benefits. The manner in which such synchrony is achieved within individual swarms deserves further study. 
Acknowledgements. We would like to thank Gwen Fenton for valuable assistance throughout all stages of this study. Thanks are also extended to Ron Mawbey, Alan Dumphy, Richard Holmes and Laura Maddock for help with equipment, and David Ratkowsky, Leon Barmuta, Peter Convey and Lloyd Peck for statistical advice and comments on earlier drafts of this manuscript.

\section{LITERATURE CITED}

Berrill M (1969) The embryonic behaviour of the mysid shrimp, Mysis relicta. Can J Zool 47:1217-1221

Branford JH (1978) The influence of daylength, temperature and season on the hatching rhythm of Homarus gammarus. J Mar Biol Assoc UK 58:639-658

Clutter RI (1969) The microdistribution and social behavior of some pelagic mysid shrimps. J Exp Mar Biol Ecol 3:125-155

DeCoursey P (1979) Egg hatching rhythms in three species of fiddler crabs. In: Naylor E, Hartnoll RG (eds) Cyclic phenomena in marine plants and animals. Proceedings of the 13th European Marine Biological Symposium. Pergamon Press, Oxford, p 399-406

DeCoursey P (1983) Biological timing. In: Vernberg FJ, Vernberg WB (eds) The biology of crustacea 8. Academic Press, New York, p 107-162

DeVries MC, Rittschof D, Forward RB Jr (1991) Chemical mediation of larval release behaviours in the crab Neopanope sayi. Biol Bull 180:1-11

Emlen ST (1984) Cooperative breeding in birds and mammals. In: Krebs JR, Davies NB (eds) Behavioural ecology: an evolutionary approach. Sinauer, Sunderland, p 305-339

Ennis GP (1973) Endogenous rhythmicity associated with larval hatching in the lobster Homarus gammarus. J Mar Biol Assoc UK 53:531-538

Fenton GE (1992) Population dynamics of Tenagomysis tasmaniae Fenton, Anisomysis mixta australis Zimmer and Paramesopodopsis rufa Fenton from south-eastern Tasmania (Crustacea: Mysidacea). Hydrobiologia 246:173-193

Fenton GE (1994) Breeding biology of Tenagomysis tasmaniae Fenton, Anisomysis mixta australis (Zimmer) and Paramesopodopsis rufa Fenton from south-eastern Tasmania (Crustacea: Mysidacea). Hydrobiologia 287:259-276

Fenton GE (1996) Production and biomass of Tenagomysis tasmaniae Fenton, Anisomysis mixta australis (Zimmer) and Paramesopodopsis rufa Fenton from south-eastern Tasmania (Crustacea: Mysidacea). Hydrobiologia 323:23-30

Forward RB (1987) Larval release rhythms of decapod crustaceans: an overview. Bull Mar Sci 41:165-176

Forward RB, Lohmann KJ (1983) Control of egg hatching in the crab Rhithropanopeus harrisii (Gould). Biol Bull 165:154-166

Friend JA, Richardson AMM (1986) Biology of terrestrial amphipods. Annu Rev Entomol 31:25-48

Green JM (1970) Observations on the behaviour and larval development of Acanthomysis sculpta (Tattersall), (Mysidacea). Can J Zool 48:289-292

Holland DL, East J, Gibson KH, Clayton E, Oldfield A (1985) Identification of the hatching factor of the barnacle Balanus balanoides as the novel eicosanoid 10,11,12trihydroxy-5, 8,14,17-eicosatetraenoic acid. Prostaglandins 29:1021-1029

Johnston NM, Fenton GE, Ritz DA (1997) Larval development in Tasmanian coastal mysids: Anisomysis mixta australis (Zimmer), Paramesopodopsis rufa Fenton and Tenagomysis tasmaniae Fenton (Peracarida: Mysidacea). Mar Biol 130:93-99

Mauchline J (1980) The biology of mysids and euphausiids. Adv Mar Biol 18:3-372

McCoy JL, Leachman A (1982) Aggregation of ovigerous rock lobsters, Jasus edwardsii (Decapoda: Palinuridae) NZ J Mar Freshw Res 16:141-146

Metillo EB, Ritz DA (1993) Predatory feeding behaviour in Paramesopodopsis rufa Fenton (Crustacea: Mysidacea). J Exp Mar Biol Ecol 170:127-141

Modlin RF (1990) Observations on the aggregative behaviour of Mysidium columbiae, the Mangrove mysid. Mar Ecol 11:263-275

Morgan SG, Christy JH (1994) Plasticity, constraint, and optimality in reproductive timing. Ecology 75:2185-2203

Morgan SG, Christy JH (1995) Adaptive significance of the timing of larval release by crabs. Am Nat 145:457-479

O'Brien DP (1988) Direct observations of clustering (schooling and swarming) behaviour in mysids (Crustacea: Mysidacea). Mar Ecol Prog Ser 42:235-246

Pulliam HR, Caraco T (1984) Living in groups: is there an optimal group size? In: Krebs JR, Davies NB (eds) Behavioural ecology: an evolutionary approach. Blackwell Scientific Publications, Oxford, p 122-147

Reitsema LA, Neff JM (1980) A recirculating artificial seawater system for the laboratory culture of Mysidopsis almyra (Crustacea; Peracarida). Estuaries 3:321-323

Ritz DA (1994) Social aggregation in pelagic invertebrates. Adv Mar Biol 30:155-216

Ritz DA (1997) Costs and benefits as a function of group size: experiments on a swarming mysid, Paramesopodopsis rufa Fenton. In: Parrish JK, Hamner WM (eds) Animal groups in three dimensions: how species aggregate. Cambridge University Press, Cambridge, p 194-206

Ritz DA (2000) Is social aggregation in aquatic crustaceans a strategy to conserve energy? Can J Fish Aquat Sci 57:1-9

Saigusa M (1981) Significance of a semilunar rhythm in the terrestrial crab Sesarma. Biol Bull Mar Biol Lab Woods Hole 160:311-321

Saigusa M, Kawagoye O (1997) Circatidal rhythm of an intertidal crab, Hemigrapsus sanguinens: synchrony with unequal tide height and involvement of a light-response mechanism. Mar Biol 129:87-96

Shillaker RO, Moore PG (1987) Biology of brooding in amphipods Lembos websteri Bate and Corophium bonnellii Milne Edwards. J Exp Mar Biol Ecol 110:113-132

Warburg MR (1993) Evolutionary biology of land isopods. Springer-Verlag, Berlin

Williams JA (1979) A semi-lunar rhythm of locomotor activity and moult synchrony in the sand beach amphipod Talitrus saltator. In: Naylor E, Hartnoll RG (eds) Cyclic phenomena in marine plants and animals. Pergamon Press, New York, p 407-414

Wittmann KJ (1978) Adoption, replacement and identification of young in marine Mysidacea (Crustacea). J Exp Mar Biol Ecol 32:259-274

Wittman KJ (1981a) Comparative biology and morphology of marsupial development in Leptomysis and other mediterranean Mysidacea (Crustacea). J Exp Mar Biol Ecol 52: $243-270$

Wittmann KJ (1981b) On the breeding biology and physiology of marsupial development in Mediterranean Leptomysis (Mysidacea:Crustacea) with special reference to the effects of temperature and egg size. J Exp Mar Biol Ecol 53:261-279

Wittman KJ (1982) Investigations on the sexual biology of a Mediterranean mysid crustacean, Leptomysis lingvura G.O. Sars. Zool Anz 209:362-375

Wooldridge $\mathrm{T}$ (1981) Zonation and distribution of the beach mysid, Gastrosaccus psammodytes. J Zool 193:183-189

Zar J (1984) Biostatistical analysis. Prentice-Hall, Englewood Cliffs, NJ

Submitted: December 29, 2000; Accepted: May 8, 2001

Proofs received from author(s): November 15, 2001 